Applied nutritional investigation

\title{
Management and prevention of refeeding syndrome in medical inpatients: An evidence-based and consensus-supported algorithm
}

\author{
Natalie Friedli M.D. a , Zeno Stanga M.D. ' , Alison Culkin Ph.D., R.D. c , \\ Martin Crook M.D., Ph.D. ${ }^{\text {d }}$, Alessandro Laviano M.D. e, Lubos Sobotka M.D. , \\ Reto W. Kressig M.D. ${ }^{g}$, Jens Kondrup M.D. h, Beat Mueller M.D. a, \\ Philipp Schuetz M.D., M.P.H. ${ }^{\text {a,* }}$
}

a Medical University Department, Clinic for Endocrinology, Metabolism and Clinical Nutrition, Kantonsspital Aarau, Aarau and Medical Faculty of the University of Basel, Basel, Switzerland

${ }^{\mathrm{b}}$ Department of Endocrinology, Diabetes and Clinical Nutrition, Bern University Hospital and University of Bern, Bern, Switzerland

${ }^{\mathrm{c}}$ Department of Nutrition and Dietetics, St Mark's Hospital, Harrow, United Kingdom

d Department of Clinical Biochemistry, Lewisham Hospital NHS Trust, London, United Kingdom

e Department of Clinical Medicine, Sapienza University, Rome, Italy

${ }^{\mathrm{f}}$ Department of Medicine, Medical Faculty and Faculty Hospital Hradec Kralove, Charles University, Prague, Czech Republic

$\mathrm{g}$ University Center for Medicine of Aging, Felix Platter Hospital and University of Basel, Basel, Switzerland

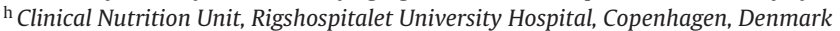

\section{A R T I C L E I N F O}

\section{Article history:}

Received 4 June 2017

Accepted 12 September 2017

\section{Keywords:}

Refeeding syndrome

Nutritional therapy

Hypophosphatemia

Treatment recommendation

\section{A B S T R A C T}

Objectives: Refeeding syndrome (RFS) can be a life-threatening metabolic condition after nutritional replenishment if not recognized early and treated adequately. There is a lack of evidence-based treatment and monitoring algorithm for daily clinical practice. The aim of the study was to propose an expert consensus guideline for RFS for the medical inpatient (not including anorexic patients) regarding risk factors, diagnostic criteria, and preventive and therapeutic measures based on a previous systematic literature search.

Methods: Based on a recent qualitative systematic review on the topic, we developed clinically relevant recommendations as well as a treatment and monitoring algorithm for the clinical management of inpatients regarding RFS. With international experts, these recommendations were discussed and agreement with the recommendation was rated.

Results: Upon hospital admission, we recommend the use of specific screening criteria (i.e., low body mass index, large unintentional weight loss, little or no nutritional intake, history of alcohol or drug abuse) for risk assessment regarding the occurrence of RFS. According to the patient's individual risk for RFS, a careful start of nutritional therapy with a stepwise increase in energy and fluids goals and supplementation of electrolyte and vitamins, as well as close clinical monitoring, is recommended. We also propose criteria for the diagnosis of imminent and manifest RFS with practical treatment recommendations with adoption of the nutritional therapy.

Conclusion: Based on the available evidence, we developed a practical algorithm for risk assessment, treatment, and monitoring of RFS in medical inpatients. In daily routine clinical care, this may help to optimize and standardize the management of this vulnerable patient population. We encourage future quality studies to further refine these recommendations.
This study was supported in part by the Swiss National Science Foundation (SNSF Professorship, PP00 P3_150531/1) and the Research Council of the Kantonsspital Aarau (1410.000.044). N.F. and Z.S. contributed equally to the manuscript. The authors have no conflicts of interest to declare.

\footnotetext{
* Corresponding author. Tel.: +41-62-838-4141; fax: +41-62-838-4100. E-mail address: schuetzph@gmail.com (P. Schuetz).
} 


\section{Introduction}

Refeeding syndrome (RFS) is an anabolic reaction caused by nutritional therapy and associated with serum electrolyte shifts, clinical symptoms, or both, resulting from metabolic changes and a fluid imbalance (e.g., peripheral edema, heart or respiratory failure). RFS is a potentially life-threatening physiologic condition that occurs in seriously malnourished patients or in patients recovering from severe catabolic diseases (e.g., sepsis, diabetic ketoacidosis) after start of nutritional therapy [1,2]. The main trigger for RFS is the switch from a catabolic to an anabolic state, which is a normal physiological reaction in the initial phase of replenishment. RFS is thus not per se an abnormal metabolic reaction of nutritional replenishment and reported incidence rates depend on the patient population (e.g., $14 \%$ of geriatric population, $25 \%$ of patients with cancer, and $28 \%$ of those with anorexia nervosa) [3-6]. In most cases, RFS has been reported to occur within first $3 \mathrm{~d}$ of starting nutritional support [6]. It occurs commonly with all types of nutritional support, but the risk appears highest in patients fed with enteral or parenteral nutrition [4]. Clinically, RFS may present with a full spectrum, including mild forms of RFS with almost no clinical signs and no risks for the patient and severe forms of RFS leading to clinical deterioration including sudden cardiac death [1]. In general, a higher mortality due to severe RFS has been found for specific patient populations, particularly older patients, patients with HIV, and critically ill patients [7-9].

Historically, RFS was first described in prisoners liberated from concentration camps in World War II $[10,11]$. It is still understudied in the inpatient population, although nutritional therapy is one of the most commonly used inhospital treatments. To our knowledge, no standardized and evidence-based guidelines with a common definition as well as treatment recommendations for RFS exist. Optimal risk assessment, establishment of a nutritional care plan, and monitoring of patients at risk for RFS have the potential to lower the morbidity and mortality associated with RFS.

\section{Methods}

\section{Current evidence on RFS}

Recently, we conducted a systematic review about RFS aiming to find evidencebased criteria regarding definition, incidence rates, time patterns of occurrence, association with adverse clinical outcomes, risk factors, and therapeutic and preventive strategies [12]. Randomized and observational clinical studies investigating RFS in anorexic and nonanorexic adult or adolescent patients (medical and surgical) were considered eligible for this review. The initial systematic search identified 2910 potentially eligible titles and abstracts. After duplicate removal, 2205 records were screened, and 69 full texts were assessed for eligibility. Most studies were excluded as RFS was not the main focus. Through two updated searches in mid-September and mid-December 2015, two additional studies were added. The final review included 45 studies with a 6608 patients. Of these, 16 studies focused on patients with anorexia nervosa and three had an interventional design. We did not find any differences among studies with and without anorexia nervosa patients regarding the main research questions. Nevertheless, patients anorexia nervosa are thought to be different from a pathophysiological perspective; therefore, we decided to only include patients without anorexia for the proposed algorithm [13].

When analyzing all studies included in the systematic search, we found heterogeneous definitions for RFS: Some studies focusing only on serum electrolyte disturbances, whereas others also used clinical parameters to establish the diagnosis. There was a large variation regarding incidence rates, varying between $0 \%$ and $80 \%$, depending on patient population and definition criteria used in the studies. Eleven studies reported data regarding the time point of RFS onset. Most cases of RFS occurred within the first 72 h after initiation of nutritional replenishment, and risk for RFS decreased strongly thereafter.

Most included studies also found the risk factors proposed by the National Collaborating Centre for Acute Care (NICE) guidelines to be associated with RFS [14]. Older age, enteral feeding, and higher malnutrition risk scores (i.e., Nutritional Risk Screening [NRS] $\geq 3$ points [15]) were additionally reported to identify patients at risk. Little information with controversial conclusions was found regarding associations of RFS and adverse outcomes and regarding the effect of preventive measures and treatment algorithms.

\section{Results}

\section{Aims of this consensus study}

The results of the recent systematic review [12] are valuable to better understand current evidence from clinical studies regarding RFS. However, in addition to a profound pathophysiological understanding of the metabolic aspects, specific recommendations and treatment algorithms are of utmost importance for clinicians working with patients at risk for RFS. Herein, the aim of this study was to propose an expert's consensus recommendation for RFS regarding pathophysiological aspects, clinical manifestations, risk factors, diagnostic criteria, and preventive and therapeutic measures. Specifically, we focused on clinically relevant questions for the management of RFS in medical inpatients, starting with risk assessment, diagnostic criteria, and management throughout the hospital.

Table 1

Metabolic functions of intracellular electrolytes

Phosphate

Phosphate $\left(\mathrm{PO}_{4}\right)$ is important for intracellular metabolism of proteins, lipids, and carbohydrates and it is a major component in phospholipid membranes, RNAs, nicotinamide diphosphate (an enzymatic cofactor), cyclic adenine and guanine nucleotides (second messengers), and phosphoproteins. It is involved in cellular regulatory processes like protein phosphorylation/dephosphorylation, mitochondrial energy production, and energy transfer (e.g., generation of ATP, creatine phosphate). Phosphate is a component of 2,3-diphosphoglycerate, which regulates the release of oxygen from hemoglobin to tissues. Furthermore, phosphate has a regulatory role in the glycolysis and hydroxylation of cholecalciferol. It is also an important acid base buffer.

Note: Phosphor (P) is present as $\mathrm{PO}_{4}$ in biological systems; it is the concentration of elemental (or inorganic) phosphorus that is measured in the clinical laboratory, although the terms phosphorus and phosphate tend to be used interchangeably. As long as molar concentrations are used, the phosphorous and phosphate concentration can be used interchangeably as they refer to the same (molar) amount of phosphate in a given volume.

Magnesium

Magnesium has a widespread physiological role in maintaining neuromuscular functions and enzymatic functions. It is an essential component for ATP

stabilization, acting as a cofactor for phosphorylation of ATP from ADP, and for many enzymatic processes.

Potassium and Sodium

The sodium-potassium membrane gradient is an indispensable condition for membrane excitation, signal transduction, and transport processes. This is partly due to the larger hydration shell of sodium, which prevents spontaneous membrane transport and ideally keeps the extracellular volume. In contrast, the smaller hydration shell of potassium allows free exchange and potassium shift to cells during growth and anabolism. Importantly, although the amount of sodium in natural food is low with higher amounts of potassium, magnesium, and $\mathrm{PO}_{4}$, the opposite is true for processed foods. This may explain why the metabolic changes during refeeding were safe in our ancestors but are more problematic with the high salt intake of common modern diets. 


\section{Pathophysiological aspects of RFS}

The membrane concentration gradients of all electrolytes between the intracellular and extracellular compartments are the basic conditions of life of the eukaryote cells [16,17]. The intracellular electrolytes are tightly connected with their metabolic functions (Table 1). Inevitably, a consequence of catabolic processes (e.g., fasting, stress reaction, inflammation) is a cellular loss of intracellular ions (potassium, phosphate, magnesium), which results in a very transient increase of circulating levels and is followed by a bodily loss due to immediate urinary excretion in exchange with sodium, which is retained during all catabolic situations. Sodium retention is therefore a universal component of stress response, inflammation, and starvation. RFS is the result of a feeding-induced disturbance of adapted homeostatic cell function, on the basis of sodium retention and low body stores of potassium, phosphate, and magnesium, possibly combined with an anabolism-induced interorgan shift, which forces already depleted stores from some tissues to other tissues with a higher rate of metabolism.

Overly rapid refeeding with processed food, particularly with carbohydrates, may precipitate a number of metabolic and pathophysiological complications, which adversely affect the cardiac, respiratory, hematologic, hepatic, neurologic, and neuromuscular systems and lead to clinical complications and even death [18]:

- Hypokalemia due to rapid cellular uptake of potassium as glucose and amino acids are taken up during cellular synthesis of glycogen and protein; potassium is the main intracellular cation balancing the negative charges on proteins.

- Hypophosphatemia due to increased phosphorylation of glucose and other high-energy phosphorylated molecules (e.g., adenosine triphosphate [ATP], creatin phosphate [PCr]) synthesis. Nutrition rich in carbohydrate and calcium can reduce serum phosphate (calcium is a binder of phosphate; carbohydrate leads to a intracellular shift of phosphate due to increased insulin levels), and meals with high phosphate contents, such as dairy products, can increase serum phosphate. Therefore, accurate phosphate concentration assessment in serum should be performed before and during feeding. Additionally, hypophosphatemia has been demonstrated to increase insulin resistance considerably; therefore, medical staff in charge should be aware of this condition because it can cause and maintain hyperglycemia, a common condition in starved patients [19].

- Hypomagnesemia due to cellular uptake, also involved in ATP synthesis.

- Sodium and water retention leading to edema and heart failure. This may be aggravated in case of preexisting pathology of the heart or thiamine deficiency.

- Thiamine pyrophosphate, the active form of thiamine (vitamin $B_{1}$ ), is involved in several enzyme functions associated with the metabolism of carbohydrates, branched-chain amino acids, and fatty acids.

In severe nutritional depletion, atrophy of the gut mucosa and impairment of pancreatic function may predispose to severe diarrhea after oral or enteral refeeding, precipitating further electrolyte and mineral imbalance [20].

\section{Discussion}

Clinical manifestations of RFS

Refeeding of patients after a time period of low food intake causes a shift in metabolism from a catabolic to an anabolic state.
The potassium, phosphate, and magnesium requirements in the cell increase during this time period. Ultimately, RFS reflects uncovered requirements of unbalanced nutrition support with a depletion of electrolytes and vitamins, causing clinical symptoms in patients. Severe hypophosphatemia $(<0.32 \mathrm{mmol} / \mathrm{L})$ causes impaired neuromuscular function with paresthesia, seizures, cramps, or impaired musculoskeletal function, including weakness and impaired muscular contractility. The disturbance of muscles of the ventilatory system causes hypoventilation and eventually respiratory failure. Rhabdomyolysis has been described as result of severe hypophosphatemia [18]. Phosphate deficiency also causes thrombocytopenia, impaired blood clotting, and deficiency in leukocyte function (impaired chemotactic, phagocytic, and bactericidal ability) because the metabolic rate of blood cell function is regulated by serum phosphate [21,22]. The red blood cells are indeed less flexible and show an impaired ability to release oxygen to the target organs [23]. This acquired dysfunction of the red and white blood cells can be improved with adequate phosphate substitution [22,23]. Other psychological effects of low phosphate include perturbed mental state, confusion, and eventually coma [18]. A moderate decrease in the plasma concentrations of magnesium $(<0.50 \mathrm{mmol} /$ $\mathrm{L})$, potassium $(<2.5 \mathrm{mmol} / \mathrm{L})$, or both, in combination with possible other interorgan electrolyte shifts or medication side effects (e.g., prolongation of QTc), can lead to cardiac arrhythmias and cardiac arrest. Both hypomagnesemia and hypokalemia lead to neuromuscular and other dysfunction, such as weakness, paralysis, paresthesia, confusion, rhabdomyolysis, and respiratory depression [18].

Cardiac atrophy as well as electrolyte abnormalities, including sinus bradycardia and a prolonged QTc interval, may be present in severe and prolonged malnutrition. These changes make the heart more vulnerable to hypophosphatemia and hypokalemia with ventricular arrhythmias and risk for sudden death, especially if the QTc interval exceeds $470 \mathrm{~ms}$ [24].

Sodium retention due to starvation, stress, and inflammation is further aggravated by the increased insulin release during refeeding and the resulting extracellular fluid expansion. Together with thiamine deficiency, this leads to accelerated heart rate, enlargement of the heart, severe edema, and ultimately to congestive heart failure with lung edema ("wet beriberi") [25]. This is more pronounced in patients with reduced cardiac muscle mass due to malnutrition. Thiamine is not stored in significant amounts in the body, so any acceleration of carbohydrate metabolismfor which thiamine is an important cofactor-may precipitate acute deficiency [26]. Thiamine deficiency also leads to the typical neurologic sequelae within the syndrome of Wernicke's encephalopathy ("cerebral beriberi”) [25]. The Wernicke-Korsakoff syndrome results in persistent alterations in memory formation, along with encephalopathy-related symptoms. Beriberi was first described as early as 2600 BC. Thiamine deficiency also affects the peripheral nervous systems and results in neuropathy ("dry beriberi") [25]. Typical symptoms are the "burning feet syndrome" and diminished sensation and weakness in legs and arms. Additionally, a decrease in the activity of thiamine-dependent enzymes limits the conversion of pyruvate to acetyl-coenzyme A and the utilization of the citric acid cycle (also known as the Krebs cycle), leading to accumulation of pyruvate and lactate. Lactic acidosis, a condition resulting from the accumulation of lactate, often is associated with nausea, vomiting, and severe abdominal pain ("gastrointestinal beriberi") [27].

Most clinical symptoms that occur during a manifest RFS are unspecific. In daily practice, the main symptoms, which should be related to a manifest RFS are tachycardia, tachypnea, and 
Table 2

Consensus opinion on management of RFS in medical inpatients

\begin{tabular}{|c|c|c|}
\hline Topic & Recommendations & Agreement \\
\hline General & $\begin{array}{l}\text { RFS can occur in medical inpatients and is associated with adverse outcome if left untreated. Risk } \\
\text { assessment, establishment of a care plan, and monitoring of patients during nutritional therapy are } \\
\text { important to reduce RFS-related morbidity. }\end{array}$ & Strong \\
\hline \multirow[t]{2}{*}{ Patients at risk for RFS } & Which medical inpatients are at risk for RFS? & \multirow[t]{2}{*}{ Strong } \\
\hline & $\begin{array}{l}\text { NICE guidelines criteria seem to be accurate for identification of patients at high risk for RFS with } \\
\text { starvation being the most important risk factor. Other criteria such as older age, low baseline serum } \\
\text { magnesium concentrations, high malnutrition risk scores (i.e., NRS } 2002 \geq 3 \text { points), or overcoming } \\
\text { severe catabolic disease together with aggressive use of enteral or parenteral feeding maybe } \\
\text { considered as additional risk factors for development of RFS. }\end{array}$ & \\
\hline \multirow{2}{*}{$\begin{array}{l}\text { Initial treatment of high-risk patients and } \\
\text { prophylactic measures to prevent RFS }\end{array}$} & How should high-risk patients be treated to prevent RFS? & \multirow[t]{2}{*}{ Moderate } \\
\hline & $\begin{array}{l}\text { Patients at high risk for RFS should receive substitution of lower-than-normal electrolytes } \\
\text { (magnesium }<0.70-0.75 \mathrm{mmol} / \mathrm{L} \text {, phosphate }<0.80 \mathrm{mmol} / \mathrm{L} \text {, potassium }<3.5 \mathrm{mmol} / \mathrm{L} \text { ). Additionally, } \\
\text { patients should be treated with vitamin } \mathrm{B}_{1} \text { (thiamine) and multivitamins. In those patients, } \\
\text { nutritional therapy should be started with reduced caloric targets and a slow increase to the full } \\
\text { caloric amount over } 5 \text { to } 10 \mathrm{~d} \text { according to the individual risk category for RFS. Fluid overload should } \\
\text { be prevented by restricted use of fluid and sodium restricted diet within the first } 7 \mathrm{~d} \text {. We recommend } \\
\text { prophylactic supplementation of electrolytes, thiamine, and minerals before initiation of nutritional } \\
\text { support in patients at risk for RFS. No iron substitution within the first } 7 \mathrm{~d} \text { even if patients have iron } \\
\text { deficiency. }\end{array}$ & \\
\hline \multirow[t]{2}{*}{ RFS monitoring } & How should we monitor patients at risk for RFS? & \multirow[t]{2}{*}{ Strong } \\
\hline & $\begin{array}{l}\text { Electrolyte concentrations should be monitored daily during the first } 72 \mathrm{~h} \text { of nutritional therapy with } \\
\text { additional clinical examination to detect signs and symptoms of fluid overload in patients at risk for } \\
\text { RFS. }\end{array}$ & \\
\hline \multirow[t]{2}{*}{ Diagnostic criteria for RFS } & Which diagnostic criteria should be used for RFS? & \multirow[t]{2}{*}{ Strong } \\
\hline & $\begin{array}{l}\text { Based on electrolyte concentrations and clinical symptoms, imminent and manifest RFS may be } \\
\text { distinguished. Imminent RFS is present if shift in electrolytes (decrease of phosphate from baseline } \\
>30 \% \text { or }<0.6 \mathrm{mmol} / \mathrm{L} \text { or any two other electrolyte shifts below normal range) occurs within } 72 \mathrm{~h} \text { after } \\
\text { start of nutrition therapy, whereas manifest RFS is considered if any electrolyte shifts occur in } \\
\text { conjunction with typical clinical symptoms. }\end{array}$ & \\
\hline \multirow[t]{2}{*}{ Treatment of RFS } & How should we treat imminent or manifest RFS? & \multirow[t]{2}{*}{ Strong } \\
\hline & $\begin{array}{l}\text { In the case of imminent or manifest RFS, electrolyte supplementation should be started or adapted. If } \\
\text { patients suffer from manifest RFS with edema, lung failure, or heart failure, the caloric target should } \\
\text { be reduced as in high-risk patients and adequate treatment for those conditions is needed. }\end{array}$ & \\
\hline
\end{tabular}

NICE, National Collaborating Centre for Acute Care; NRS, Nutritional Risk Screening; RFS, refeeding syndrome

peripheral edema $[18,28]$. However, in medical inpatients with different diseases, such symptoms may be due to other conditions, including pulmonary embolism or acute heart failure.

\section{Which medical inpatients are at risk for RFS?}

Table 2 summarizes the consensus on the different recommendations. Most of the clinical trials focusing on risk factors for RFS are in agreement with criteria proposed by the NICE guidelines [14,29-34]. Still, Goyale [35] and Zeki [36] reported low sensitivity and specificity of these factors to predict RFS. The NICE guidelines were published in 2006 and deal with nutrition support, enteral tube feeding, and parenteral nutrition in adults. These guidelines propose low body mass index, large unintentional weight loss in a short time period, little or no nutritional intake for $\sim 5$ to $10 \mathrm{~d}$, or a history of alcohol or drug misuse (including insulin, chemotherapy, antacids, or diuretics) as risk factors for RFS in patients started on nutritional therapy.

Rio et al. [34] found starvation and low baseline serum magnesium concentration to be independent predictors for RFS, but to our knowledge, no other studies have yet validated these findings. Furthermore, low prealbumin or albumin concentration [3,37-39], use of enteral nutrition [3,36,40], and higher amounts of nutritional intake during nutritional therapy $[8,31,41]$ were found to be risk factors. However, some studies did not find that these factors predicted RFS, although some of the studies were small in size with risk for type II errors $[37,42,43]$.

Thus, based on the available evidence, risk criteria proposed by the NICE guidelines seem to be adequate to identify patients at high risk for RFS with prolonged starvation being the most important risk factor. Additionally, there may be other risk factors, such as older age, low baseline serum magnesium concentrations, high malnutrition risk scores (i.e., NRS $2002 \geq 3$ points) [15], or severe catabolic disease in conjunction with the use of enteral or parenteral feeding. Also, because RFS is potentially preventable and associated with life-threatening consequences, initial risk assessment for RFS should be done in patients before start of nutritional replenishment using the same risk factors (Fig. 1 and Table 1). To differentiate between no risk, low risk, high risk, and very high risk for RFS, we adapted the NICE guidelines and added additional criteria for the very high-risk category.

\section{How should high-risk patients be treated to prevent RFS?}

Several trials [29,32] found prophylactic administration of phosphate and thiamine in patients at risk for RFS to be effective to prevent hypophosphatemia, RFS, and mortality and adverse outcome during nutritional replenishment. Only three studies showed no such effect. This is in agreement with a pathophysiological view in which intracellular electrolytes and vitamins are depleted in patients with deteriorating nutritional status, and after the start of nutritional therapy, the sudden flux into the cells leads to a drop of plasma levels. Especially hypophosphatemia is the result of restarting metabolism with the initiation of nutritional replenishment in starved patients. Therefore, preventive supplementation of phosphate in patients at high and very high RFS risk should be considered, even if the phosphate concentration is still in the low normal range. Of note, during starvation there is phosphate outflow from the cells into the blood; thus, plasma phosphate levels are often still in the normal range before 


\begin{tabular}{|c|c|c|c|c|c|c|}
\hline \multicolumn{7}{|c|}{ 1. Initial Risk Assessment } \\
\hline \multicolumn{3}{|c|}{$\begin{array}{l}\text { Minor risk factors } \\
\text { BMl }<18.5 \mathrm{~kg} / \mathrm{m}^{2} \\
\text { Unintentional weight loss }>10 \% \text { in the past } 3-6 \\
\text { mo } \\
\text { Little or no nutritional intake for }>5 \mathrm{~d} \\
\text { History of alcohol abuse or drugs including } \\
\text { insulin, chemotherapy, antacids, or diuretics }\end{array}$} & \multicolumn{2}{|c|}{$\begin{array}{ll}\text { Major risk factors } \\
\text { BMl }<16 \mathrm{~kg} / \mathrm{m}^{2} \\
\text { Unintentional weight loss }>15 \% \text { in the past 3-6 } \\
\text { mo } \\
\text { Little or no nutritional intake for }>10 \mathrm{~d} \\
\text { - } \quad \text { Low baseline levels of potassium, phosphate, or } \\
\text { magnesium before feeding }\end{array}$} & \multicolumn{2}{|c|}{$\begin{array}{l}\text { Specific patient populations at high risk } \\
\text { (careful assessment is recommended) } \\
\text { - Hunger strike, chronic severe dieting } \\
\text { - History of bariatric surgery, short bowel syndrome } \\
\text { - Tumor patients, frail elderly patients with chronic } \\
\text { debilitating disease }\end{array}$} \\
\hline \multicolumn{7}{|c|}{ 2. Prevention of RFS During Nutritional Therapy } \\
\hline 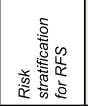 & No Risk & \multicolumn{2}{|c|}{$\begin{array}{l}\text { Low Risk } \\
1 \text { minor risk factor }\end{array}$} & \multicolumn{2}{|c|}{$\begin{array}{l}\text { High Risk } \\
1 \text { major or } 2 \text { minor risk factors }\end{array}$} & 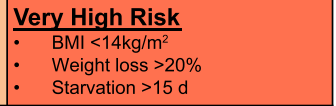 \\
\hline \multirow{2}{*}{ 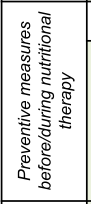 } & \multicolumn{6}{|c|}{ Careful restoration of fluid balance to avoid fluid overload (see Table 1): \% dehydration $\times$ BW $(\mathrm{kg})=$ volume to be replaced in L (rough estimate of fluid loss) } \\
\hline & $\begin{array}{l}\text { No other preventive measures } \\
\text { needed }\end{array}$ & \multicolumn{5}{|c|}{$\begin{array}{l}\text { Depending on the risk, consider electrolyte substitution if lower than normal/in low normal range }{ }^{*} \text { with daily } \\
\text { adaption according to serum levels: } 1-1.5 \mathrm{mmol} / \mathrm{kg} / \mathrm{d} \text { potassium, } 0.2-0.4 \mathrm{mmol} / \mathrm{kg} / \mathrm{d} \text { magnesium, } 0.3-0.6 \\
\mathrm{mmol} / \mathrm{kg} / \mathrm{d} \text { phosphate } \\
\text { Depending on the risk, consider other measures: use of thiamine }(200-300 \mathrm{mg} \text { on days } 1-5) \text {, Multivitamins } \\
\text { during days } 1-10, \text { replace specific deficiency of trace elements, sodium restriction }(<1 \mathrm{mmol} / \mathrm{kg} / \mathrm{d}) \text { for days } 1-7\end{array}$} \\
\hline $\begin{array}{l}\frac{1}{1} \\
\frac{1}{0} \\
\frac{0}{0} \\
0\end{array}$ & \multirow{6}{*}{$\begin{array}{l}\text { Energy (by all routes): } \\
\text { Full requirements } \\
\text { (40-60\% carbohydrates, } 30-40 \% \text { fat, } \\
15-20 \% \text { proteins) }\end{array}$} & \multirow{2}{*}{\multicolumn{2}{|c|}{\begin{tabular}{|l} 
Energy (by all routes): \\
$15-25 \mathrm{kcal} / \mathrm{kg} / \mathrm{d}$ \\
$(40-60 \%$ carbohydrates, $30-40 \%$ fat, \\
$15-20 \%$ proteins $)$ \\
Energy (by all routes): \\
$30 \mathrm{kcal} / \mathrm{kg} / \mathrm{d}$ \\
$\begin{array}{l}(40-60 \% \text { carbohydrates, } 30-40 \% \text { fat, } \\
15-20 \% \text { proteins) }\end{array}$ \\
\end{tabular}}} & \multicolumn{2}{|c|}{$\begin{array}{l}\text { Energy (by all routes): } \\
10-15 \mathrm{kcal} / \mathrm{kg} / \mathrm{d} \\
(40-60 \% \text { carbohydrates, } 30-40 \% \text { fat, } \\
15-20 \% \text { proteins) }\end{array}$} & $\begin{array}{l}\text { Energy (by all routes): } \\
5-10 \mathrm{kcal} / \mathrm{kg} / \mathrm{d} \\
\text { (40-60\% carbohydrates, } 30-40 \% \text { fat, } \\
15-20 \% \text { proteins) }\end{array}$ \\
\hline 㐫 & & & & \multirow{2}{*}{\multicolumn{2}{|c|}{$\begin{array}{l}\text { Energy (by all routes): } \\
15-25 \mathrm{kcal} / \mathrm{kg} / \mathrm{d} \\
\text { (40-60\% carbohydrates, } 30-40 \% \text { fat, } \\
15-20 \% \text { proteins) }\end{array}$}} & \multirow{3}{*}{$\begin{array}{l}\text { Energy (by all routes): } \\
10-20 \mathrm{kcal} / \mathrm{kg} / \mathrm{d} \\
(40-60 \% \text { carbohydrates, } 30-40 \% \text { fat, } \\
15-20 \% \text { proteins) }\end{array}$} \\
\hline के & & \multirow{4}{*}{\multicolumn{2}{|c|}{$\begin{array}{l}\text { Energy (by all routes): } \\
\text { full requirements } \\
\text { (40-60\% carbohydrates, } 30-40 \% \text { fat, } \\
15-20 \% \text { proteins) }\end{array}$}} & & & \\
\hline $\begin{array}{l}\overleftarrow{6} \\
\stackrel{\oplus}{0}\end{array}$ & & & & \multicolumn{2}{|c|}{$\begin{array}{l}\text { Energy (by all routes): } \\
30 \mathrm{kcal} / \mathrm{kg} / \mathrm{d} \\
\text { (40-60\% carbohydrates, } 30-40 \% \text { fat, } \\
15-20 \% \text { proteins) }\end{array}$} & \\
\hline $\begin{array}{l}5 \\
\frac{1}{1} \\
0 \\
0 \\
0 \\
0\end{array}$ & & & & \multirow{2}{*}{\multicolumn{2}{|c|}{$\begin{array}{l}\text { Energy (by all routes): } \\
\text { full requirements } \\
\text { (40-60\% carbohydrates, } 30-40 \% \text { fat, } \\
15-20 \% \text { proteins) }\end{array}$}} & $\begin{array}{l}\text { Energy (by all routes): } \\
20-30 \mathrm{kcal} / \mathrm{kg} / \mathrm{d} \\
(40-60 \% \text { carbohydrates, } 30-40 \% \text { fat, } \\
15-20 \% \text { proteins) }\end{array}$ \\
\hline $\begin{array}{l}\frac{1}{5} \\
\frac{1}{1}\end{array}$ & & & & & & $\begin{array}{l}\text { Energy (by all routes): } \\
\text { full requirements } \\
\text { (40-60\% carbohydrates, } 30-40 \% \text { fat, } \\
15-20 \% \text { proteins) }\end{array}$ \\
\hline Fluids & No restriction in fluids & $\begin{array}{l}\text { Fluid } \\
\text { appr }\end{array}$ & $\begin{array}{l}\text { Is to maintain zero balance, } \\
\text { ox. } 30-35 \mathrm{~mL} / \mathrm{kg} / \mathrm{d}\end{array}$ & \multicolumn{2}{|c|}{$\begin{array}{l}\text { Fluids to maintain zero balance, days } 1-3 \\
25-30 \mathrm{~mL} / \mathrm{kg} / \mathrm{d} \text {, >days } 430-35 \mathrm{~mL} / \mathrm{kg} / \mathrm{d}\end{array}$} & \begin{tabular}{|l|} 
Fluids to maintain zero balance, \\
days $1-320-25 \mathrm{~mL} / \mathrm{kg} / \mathrm{d}$, days $4-6$ \\
$25-30 \mathrm{~mL} / \mathrm{kg} / \mathrm{d},>$ days $725-35 \mathrm{~mL} / \mathrm{kg} / \mathrm{d}$
\end{tabular} \\
\hline Salt & No restriction in salt intake & No $r$ & estriction in salt intake & \multicolumn{2}{|c|}{ Restrict $\mathrm{Na}$ to $<1 \mathrm{mmol} / \mathrm{kg} / \mathrm{d}$ (days $1-7$ ) } & Restrict $\mathrm{Na}$ to $<1 \mathrm{mmol} / \mathrm{kg} / \mathrm{d}$ (days $1-10$ ) \\
\hline Iron & \multicolumn{6}{|c|}{ No iron substitution within the first $7 \mathrm{~d}$ even if patients have iron deficiency } \\
\hline Monitoring & & & $\begin{array}{l}\text { - Assessment of serum el } \\
\text { - Daily clinical examinatio } \\
\text { - Continuous monitoring o }\end{array}$ & $\begin{array}{l}\text { yte levels dail } \\
\text { sing on hydr } \\
\text { cardiac rhythr }\end{array}$ & $\begin{array}{l}3 \text {, then every } 2-3 \\
\text { (1-2 times per da) } \\
\text { ocardiogram daily in }\end{array}$ & $\begin{array}{l}\text { d } \\
\text { y) } \\
\text { ? patients at very high risk for RFS }\end{array}$ \\
\hline \multicolumn{7}{|c|}{$\begin{array}{l}\text { ssment and Diagnosis During Nutritional Therapy } \\
\text { (for all risk categories) }\end{array}$} \\
\hline \multirow{5}{*}{ 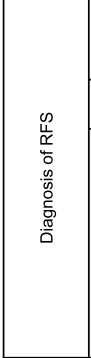 } & \multicolumn{6}{|c|}{$\begin{array}{l}\text { Shift in electrolytes within } 72 \mathrm{~h} \text { after start of nutrition therapy: } \\
\text { - Decrease of phosphate from baseline }>30 \% \text { or }<0.6 \mathrm{mmol} / \mathrm{L} \\
- \text { Or any } 2 \text { other electrolyte shifts below normal range }\left(\mathrm{Mg}<0.75 \mathrm{mmol} / \mathrm{L}, \mathrm{PO}_{4}<0.80 \mathrm{mmol} / \mathrm{L}, \mathrm{K}<3.5 \mathrm{mmo} / \mathrm{L}\right)\end{array}$} \\
\hline & NO $\downarrow$ & \multicolumn{5}{|c|}{ YES $\downarrow$} \\
\hline & \multirow{3}{*}{$\begin{array}{l}\text { No RFS } \\
\text { No change of therapy algorithm. } \\
\text { Substitution of electrolytes if they } \\
\text { drop below reference range. }\end{array}$} & \multicolumn{5}{|c|}{ Associated with clinical symptoms ${ }^{\ddagger} ?$} \\
\hline & & \multirow{2}{*}{\multicolumn{3}{|c|}{$\begin{array}{l}\text { Imminent RFS } \\
\text { Start and/or adapt electrolyte substitution. Repeat } \\
\text { assessment every } 2-3 \text { d. }\end{array}$}} & & YES $\downarrow$ \\
\hline & & & & & $\begin{array}{l}\text { Manifest RFS } \\
\text { Increase electrolyte } \\
\text { conditions adequat } \\
\text { high-risk patients. F }\end{array}$ & $\begin{array}{l}\text { substitution and treat clinical } \\
\text { ely. Adapt nutrition therapy as in } \\
\text { Repeat assessment every day. }\end{array}$ \\
\hline
\end{tabular}

Fig. 1. Guidelines for management and prevention of RFS in medical inpatients receiving nutritional therapy. BMI, body mass index; BW, body weight; K, potassium; $\mathrm{Mg}$, magnesium; Na, sodium; $\mathrm{PO}_{4}$, phosphate; RFS, refeeding syndrome. * Mg < 0.70-0.75 mmol/L, PO4 <0.80 mmol/L, K<3.5 mmol/L. †Individual clinical judgment is recommended for deciding the optimal rate to increase nutritional support in order to reach the full target in all three phases of the replenishment/feeding period. †Clinical symptoms:

- Most common: tachycardia, tachypnea, edema

- Other possible signs:

Cardiac: hyper-/hypotension, congestive heart failure, cardiomyopathy, sudden death

Pulmonary: failure or ventilator dependency, pulmonary edema

Neurologic: weakness, paresthesia, altered mental state, seizure, ataxia, tremor, vertigo, tetany, rhabdomyolysis, myalgia

Hematologic: platelet dysfunction, hemolytic anemia, leukocyte dysfunction

Gastrointestinal: constipation, abdominal pain, diarrhea, anorexia, paralytic ileus

Renal: decreased ability to concentrate urine

Metabolic: alkalosis, glucose intolerance, hypernatremia, ketoacidosis, metabolic acidosis. 
start of feeding despite deficiencies in storage levels. In patients with renal failure, phosphate supplementation should be administered carefully. Thiamine should also be administered preventively before initiation of nutritional therapy, independent of blood levels. Also, deficiencies of other electrolytes such as potassium and magnesium should be corrected if levels are below the normal range. To prevent fluid overload, sodium and fluid should be restricted to the minimum necessary for restoring sodium and water balance.

Regarding nutritional therapy, evidence from several studies and guidelines supports the concept of lowering energy intake in patients at risk for RFS during the initial phase of nutritional support $[14,44,29,45]$. Still, in their prospective observational trial, Rio et al. [34] did not find a preventive effect of hypocaloric feeding with regard to RFS, but risk for RFS was generally low and the study was thus underpowered. In fact, only 3 of 243 patients were diagnosed with RFS defined by clinical criteria and laboratory abnormalities. Also, the study was not randomized, making causal inference impossible. Importantly, a recent high-quality randomized trial authored by Doig et al. [9] in 339 critically ill adults admitted to intensive care found caloric restriction to be an effective measure to prevent RFS. Mortality on day 60 after study inclusion was significantly lower in the intervention group in which hypocaloric treatment was used during the initial phase of nutrition support. Although this study was not conducted in medical ward patients, it is considered the best quality evidence today regarding treatment of patients with evidence of RFS.

Today, the most widely used guideline for RFS is the recommendations published by NICE. Those guidelines recommend starting with hypocaloric feeding in patients at high risk for RFS. Based on this and the recent evidence from the study by Doig et al. [9], we recommend using a risk-adjusted low-caloric target in patients at risk for RFS. The recommended initial energy intake is based on the four risk categories (no risk, low risk, high risk, very high risk) with a gradual increase to the full caloric amount within 5 to $10 \mathrm{~d}$ (Fig. 1). Because current evidence points to beneficial effects of nutritional therapy in medical inpatients [46-48], RFS risk should not lead to suboptimal nutritional care in patients. Thus, we recommend using individual clinical judgment in deciding the best rate to increase nutrition support to reach targets in the different phases of replenishment (Fig. 1). Specifically, we decided to lower the amount of calories in the high-risk group to $10 \mathrm{kcal} / \mathrm{kg}$ despite the lack of research studies documenting that such a measure would be beneficial to the patient. Yet, there was no strong consensus about this measure within the group, and some centers have reported good clinical experience with using higher targets (i.e., $20 \mathrm{kcal} / \mathrm{kg}$ ) for the high-risk group. Also, in patients who are initially not at increased risk for RFS but who later develop RFS during nutritional replenishment, energy targets should be reduced and the feeding algorithm adapted. Additionally, we recommend careful fluid management to avoid fluid overload (Table 1).

\section{How should we monitor patients at risk for RFS?}

In a study on malnourished cancer patients started on artificial nutritional support, the incidence of the RFS defined by a phosphate concentration $<0.40 \mathrm{mmol} / \mathrm{L}$ was found to be $24.5 \%$, with a higher incidence in patient with enteral (37.5\%) compared with parenteral (18.5\%) nutrition [4]. In that study, $61.5 \%$ of patients developed the RFS within the first $3 \mathrm{~d}$ after start of feeding. In line with this, most studies reported that the RFS occurs within the first $72 \mathrm{~h}$ after start of nutritional therapy. This period seems to be the most vulnerable phase, as metabolism changes from a catabolic to an anabolic state and electrolytes as well as fluids shifts are most likely to occur. Thus, we recommend that during this initial phase, electrolytes should be monitored and clinical examination performed at least daily to detect signs and symptoms of fluid overload or impaired organ function associated with RFS. If critical electrolytes drop significantly during the refeeding period, an adequate substitution should be started preferably by oral route. In patients with gastrointestinal failure (e.g., ileus, short bowel, malabsorption), parenteral routes are preferable. Furthermore, monitoring of the cardiac rhythm is advisable by electrocardiogram in the initial refeeding phase in high-risk patients. This helps with early detection of abnormalities caused by electrolyte shifts (e.g., QT prolongation), which potentially causes severe arrhythmias (e.g., torsades de pointes).

\section{Which diagnostic criteria should be used for RFS?}

During starvation (catabolic state), the organism switches from carbohydrates/glycogen to body protein (gluconeogenesis) and fat (free fatty acids, ketogenesis) metabolism as the main source of energy. During replenishment, the sudden glucose supply results in an overwhelming increase in insulin concentrations (anabolic state), stimulating the production of glycogen, fat, and protein. Importantly, high concentrations of insulin lead to renal sodium retention with potential fluid overload. For those processes, there is a need for electrolytes and minerals that causes a depletion of the serum concentrations of potassium, phosphate, magnesium, and thiamine. Considering these physiological changes, a shift in electrolytes is the hallmark of RFS and often considered a main diagnostic criterion for RFS. Clinical symptoms such as peripheral edema, respiratory insufficiency, or heart failure resulting from these electrolyte and fluid shifts may occur in severe cases. Manifest RFS is defined as electrolyte changes and clinical symptoms, whereas imminent RFS is defined by electrolyte shifts only. A majority of studies use hypophosphatemia as the main criterion for RFS [44]. In fact, in our recent systematic review, 20 of 38 studies based their RFS definition on hypophosphatemia. Therefore, we see a shift of serum phosphate as the main diagnostic criteria of RFS, although shifts in other electrolytes may also occur and point to RFS. If, during the first $72 \mathrm{~h}$ after the start of nutrition therapy, phosphate decreases $>30 \%$ from baseline or $<0.6 \mathrm{mmol} / \mathrm{L}$, or any two other electrolyte shifts below the normal range occur, imminent RFS is highly likely. If clinical symptoms occur, manifest RFS should be considered.

\section{How should we treat imminent or manifest RFS?}

Of 45 studies included in the systematic review [12], only 3 reported on therapeutic strategies to treat RFS. Two of them reported phosphate supplementation to be effective [49,50]. Doig et al. [9] reduced energy intake for critically ill patients suffering from RFS (defined by hypophosphatemia) and showed that this measure was successful. Therefore, we recommend intensifying or starting electrolyte supplementation in case of an imminent or manifest RFS. If patients suffer from evident RFS with clinical symptoms (edema, lung or heart failure, or other organ deterioration), the energy content of nutritional replenishment should be reduced and careful fluid management should be used in high-risk patients, in addition to mandatory adequate treatment for clinical symptoms. 


\section{Limitations of current evidence and outlook}

Based on a recent systematic review on RFS [12] and pathophysiological considerations, we developed a treatment algorithm for the nutritional care of malnourished medical inpatients to prevent RFS. Current evidence is in line with former NICE guidelines and updated with recent trial data. Most of trial data used for this guideline were observational but not interventional, making strong recommendations difficult. There are unanswered questions regarding why patients develop RFS and whether it is rather a physiological biological response or maladaptation [47]. Also, it is not known whether there is a difference between RFS and refeeding hypophosphatemia. Additionally, it remains unclear what the optimal calorie replacement rate is and whether it differs between patient populations (e.g., critically ill versus medical ward patients) [51]. Finally, it remains unclear whether hypo- or hyperglycemia plays a role in the manifestation of RFS and if treatment with insulin may interact with the risk for RFS.

Although several blood markers have been proposed as malnutrition biomarkers [52], there are only few reports about markers predicting the later occurrence of RFS. Some studies state that increased insulin-like growth factor- 1 in combination with an increased leptin concentration would be associated with a $30 \%$ decrease in phosphate concentration within 12 to $36 \mathrm{~h}$ after starting parenteral nutrition therapy [42]. Other markers such as cytokines may play an important role here. Finally, several reports [25-27] have shown that thiamine substitution is important to prevent Wernicke's and Korsakoff psychosis, but little is known about the potential of other vitamin and trace elements.

\section{Conclusion}

RFS is a life-threatening metabolic condition due to rapid, inadequate nutritional support in malnourished catabolic patients. High morbidity and mortality can be reduced by early diagnosis and taking appropriate measures [18]. Therefore, in-depth knowledge of this metabolic condition is essential for its prevention, recognition, and treatment. Based on a recent systematic literature review [12], we developed a practical algorithm for risk assessment, treatment, and monitoring of RFS in medical inpatients, which may help to optimize and standardize the RFS management. Still, many aspects and pathophysiological pathways of RFS remain unclear. We therefore encourage future quality studies to further refine our recommendations.

\section{References}

[1] Preiser JC, van Zanten AR, Berger MM, Biolo G, Casaer MP, Doig GS, et al. Metabolic and nutritional support of critically ill patients: Consensus and controversies. Crit Care 2015;19:35.

[2] Schuetz P. "Eat your lunch!" - controversies in the nutrition of the acutely, non-critically ill medical inpatient. Swiss Med Wkly 2015;145:w14132.

[3] Kagansky N, Levy S, Koren-Morag N, Berger D, Knobler H. Hypophosphataemia in old patients is associated with the refeeding syndrome and reduced survival. J Intern Med 2005;257:461-8.

[4] Gonzalez Avila G, Fajardo Rodriguez A, Gonzalez Figueroa E. The incidence of the refeeding syndrome in cancer patients who receive artificial nutritional treatment. Nutr Hosp 1996;11:98-101.

[5] Ornstein RM, Golden NH, Jacobson MS, Shenker IR. Hypophosphatemia during nutritional rehabilitation in anorexia nervosa: implications for refeeding and monitoring. J Adolesc Health 2003;32:83-8.

[6] Hernandez-Aranda JC, Gallo-Chico B, Luna-Cruz ML, Rayon-Gonzalez MI, Flores-Ramirez LA, Ramos Munoz R, et al. Malnutrition and total parenteral nutrition: a cohort study to determine the incidence of refeeding syndrome. Rev Gastroenterol Mex 1997;62:260-5.

[7] Lubart E, Leibovitz A, Dror Y, Katz E, Segal R. Mortality after nasogastric tube feeding initiation in long-term care elderly with oropharyngeal dysphagia-the contribution of refeeding syndrome. Gerontology 2009;55:393-7.
[8] Coskun R, Gundogan K, Baldane S, Guven M, Sungur M. Refeeding hypophosphatemia: a potentially fatal danger in the intensive care unit. Turk J Med Sci 2014;44:369-74.

[9] Doig GS, Simpson F, Heighes PT, Bellomo R, Chesher D, Caterson ID, et al. for the Refeeding Syndrome Trial Investigators Group. Restricted versus continued standard caloric intake during the management of refeeding syndrome in critically ill adults: a randomised, parallel-group, multicentre, single-blind controlled trial. Lancet Respir Med 2015;3:943-52.

[10] Schnitker MA, Mattman PE, Bliss TL. A clinical study of malnutrition in Japanese prisoners of war. Ann Intern Med 1951;35:69-96.

[11] Burger GC, Drummond DJ, Sandstead HR. Appendices to malnutrition and starvation in western Netherlands September 1944-July 1945 (part II). The Hague, Netherlands: The Hague General State Printing Office; 1948.

[12] Friedli N, Stanga Z, Sobotka L, Culkin A, Kondrup J, Laviano A, et al. Revisiting the refeeding syndrome: results of a systematic review. Nutrition 2017; 35:151-60.

[13] Garber AK, Sawyer SM, Golden NH, Guarda AS, Katzman DK, Kohn MR, et al A systematic review of approaches to refeeding in patients with anorexia nervosa. Int J Eat Disord 2016;49:293-310.

[14] Care NCCfA. Nutrition support in adults oral nutrition support, enteral tube feeding and parenteral nutrition. London, UK: National Collaborating Centre for Acute Care; 2006, Available at: https://www.ncbi.nlm.nih.gov/pubmed/ 21309138.

[15] Kondrup J, Rasmussen HH, Hamberg O, Stanga Z. Ad Hoc ESPEN Working Group. Nutritional risk screening (NRS 2002): a new method based on an analysis of controlled clinical trials. Clin Nutr 2003;22:321-36.

[16] Hearing SD. Refeeding syndrome. BMJ 2004;328:908-9.

[17] Cahill GF Jr. Fuel metabolism in starvation. Annu Rev Nutr 2006;26:1-22.

[18] Boateng AA, Sriram K, Meguid MM, Crook M. Refeeding syndrome: treatment considerations based on collective analysis of literature case reports. Nutrition 2010;26:156-67.

[19] DeFronzo RA, Lang R. Hypophosphatemia and glucose intolerance: evidence for tissue insensitivity to insulin. N Engl J Med 1980;303:1259-63.

[20] Winter TA, O'Keefe SJ, Callanan M, Marks T. The effect of severe undernutrition and subsequent refeeding on whole-body metabolism and protein synthesis in human subjects. JPEN J Parenter Enteral Nutr 2005;29:221-8.

[21] Manghat P, Sodi R, Swaminathan R. Phosphate homeostasis and disorders. Ann Clin Biochem 2014;51:631-56.

[22] Craddock PR, Yawata Y, VanSanten L, Gilberstadt S, Silvis S, Jacob HS. Acquired phagocyte dysfunction. A complication of the hypophosphatemia of parenteral hyperalimentation. N Engl J Med 1974;290:1403-7.

[23] Travis SF, Sugerman HJ, Ruberg RL, Dudrick SJ, Delivoria-Papadopoulos M, Miller LD, et al. Alterations of red-cell glycolytic intermediates and oxygen transport as a consequence of hypophosphatemia in patients receiving intravenous hyperalimentation. N Engl J Med 1971;285:763-8.

[24] Heymsfield SB, Bethel RA, Ansley JD, Gibbs DM, Felner JM, Nutter DO. Cardiac abnormalities in cachectic patients before and during nutritional repletion. Am Heart J 1978;95:584-94.

[25] Francini-Pesenti F, Brocadello F, Manara R, Santelli L, Laroni A, Caregaro L. Wernicke's syndrome during parenteral feeding: Not an unusual complication. Nutrition 2009;25:142-6.

[26] Alaei Shahmiri F, Soares MJ, Zhao Y, Sherriff J. High-dose thiamine supplementation improves glucose tolerance in hyperglycemic individuals: a randomized, double-blind cross-over trial. Eur J Nutr 2013;52:1821-4.

[27] Donnino M. Gastrointestinal beriberi: a previously unrecognized syndrome. Ann Intern Med 2004;141:898-9.

[28] Crook MA, Hally V, Panteli JV. The importance of the refeeding syndrome. Nutrition 2001;17:632-7.

[29] Hofer M, Pozzi A, Joray M, Ott R, Hahni F, Leuenberger M, et al. Safe refeeding management of anorexia nervosa inpatients: an evidence-based protocol. Nutrition 2014;30:524-30.

[30] Raj KS, Keane-Miller C, Golden NH. Hypomagnesemia in adolescents with eating disorders hospitalized for medical instability. Nutr Clin Pract 2012; 27:689-94.

[31] Vignaud M, Constantin JM, Ruivard M, Villemeyre-Plane M, Futier E, Bazin JE, et al. AZUREA Group. Refeeding syndrome influences outcome of anorexia nervosa patients in intensive care unit: an observational study. Crit Care 2010;14:R172.

[32] Eichelberger M, Joray ML, Perrig M, Bodmer M, Stanga Z. Management of patients during hunger strike and refeeding phase. Nutrition 2014;30:13728.

[33] Chen LJ, Chen HL, Bair MJ, Wu CH, Lin IT, Lee YK, et al. Refeeding syndrome in Southeastern Taiwan: Our experience with 11 cases. World J Gastroenterol 2014;20:10525-30.

[34] Rio A, Whelan K, Goff L, Reidlinger DP, Smeeton N. Occurrence of refeeding syndrome in adults started on artificial nutrition support: prospective cohort study. BMJ Open 2013;3.

[35] Goyale A. Predicting refeeding syndrome: insulin growth factor 1 (IGF-1) as a diagnostic biochemical marker for clinical practice. Clin Nutr 2013;32: S16.

[36] Zeki S, Culkin A, Gabe SM, Nightingale JM. Refeeding hypophosphataemia is more common in enteral than parenteral feeding in adult in patients. Clin Nutr 2011;30:365-8. 
[37] Gaudiani JL, Sabel AL, Mehler PS. Low prealbumin is a significant predictor of medical complications in severe anorexia nervosa. Int J Eat Disord 2014;47:148-56.

[38] Brown C, Mehler PS. Anorexia nervosa complicated by diabetes mellitus: the case for permissive hyperglycemia. Int J Eat Disord 2014;47:671-4.

[39] Marik PE, Bedigian MK. Refeeding hypophosphatemia in critically ill patients in an intensive care unit. A prospective study. Arch Surg 1996;131: 1043-7.

[40] Chen HL, Bair MJ, Lin IT, Wu CH, Lee YK. Clinical experience of refeeding syndrome in southeastern Taiwan. J Gastroenterol Hepatol 2012;27:308.

[41] Fan CG, Ren JA, Wang XB, Li JS. Refeeding syndrome in patients with gastrointestinal fistula. Nutrition 2004;20:346-50.

[42] Elnenaei MO, Alaghband-Zadeh J, Sherwood R, Awara MA, Moniz C, le Roux CW. Leptin and insulin growth factor 1 : diagnostic markers of the refeeding syndrome and mortality. Br J Nutr 2011;106:906-12.

[43] Henderson S, Boyce F, Sumukadas D, Witham MD. Changes in serum magnesium and phosphate in older hospitalised patients--correlation with muscle strength and risk factors for refeeding syndrome. J Nutr Health Aging 2010;14:872-6.

[44] Mehanna HM, Moledina J, Travis J. Refeeding syndrome: what it is, and how to prevent and treat it. BMJ 2008;336:1495-8.

[45] Stanga Z, Brunner A, Leuenberger M, Grimble RF, Shenkin A, Allison SP, et al. Nutrition in clinical practice-the refeeding syndrome: illustrative cases and guidelines for prevention and treatment. Eur J Clin Nutr 2008;62:687-94.
[46] Bally MR, Blaser Yildirim PZ, Bounoure L, Gloy VL, Mueller B, Briel M, et al. Nutritional support and outcomes in malnourished medical inpatients: a systematic review and meta-analysis. JAMA Intern Med 2016;176:4353.

[47] Schutz P, Bally M, Stanga Z, Keller U. Loss of appetite in acutely ill medical inpatients: physiological response or therapeutic target? Swiss Med Wkly 2014;144:w13957.

[48] Bounoure L, Gomes F, Stanga Z, Keller U, Meier R, Ballmer P, et al. Detection and treatment of medical inpatients with or at-risk of malnutrition: suggested procedures based on validated guidelines. Nutrition 2016;32: 790-8.

[49] Whitelaw M, Gilbertson H, Lam PY, Sawyer SM. Does aggressive refeeding in hospitalized adolescents with anorexia nervosa result in increased hypophosphatemia? J Adolesc Health 2010;46:577-82.

[50] Terlevich A, Hearing SD, Woltersdorf WW, Smyth C, Reid D, McCullagh E, et al. Refeeding syndrome: effective and safe treatment with phosphates polyfusor. Aliment Pharmacol Ther 2003;17:1325-9.

[51] Gomes F, Schuetz P, Bounoure L, Austin P, Ballesteros-Pomar M, Cederholm $\mathrm{T}$, et al. ESPEN guidelines on nutritional support for polymorbid internal medicine patients. Clin Nutr 2017, [Epub ahead of print].

[52] Felder S, Braun N, Stanga Z, Kulkarni P, Faessler L, Kutz A, et al. Unraveling the link between malnutrition and adverse clinical outcomes: association of acute and chronic malnutrition measures with blood biomarkers from different pathophysiological states. Ann Nutr Metab 2016;68:164-72. 